\title{
A autonomia dos municípios brasileiros e o desenvolvimento da integração regional de fronteira
}

\author{
Idir Canzi ${ }^{1}$ \\ Myriam Aldana Vargas ${ }^{2}$
}

\begin{abstract}
Resumo: 0 artigo tem por objetivo central problematizar sobre a autonomia dos municípios brasileiros no sistema federativo, perpassando sua análise sobre o desenvolvimento da integração regional da faixa de Fronteira entre Brasil e Argentina, a partir da instalação em 2011 dos Núcleos Estaduais de Santa Catarina e Paraná de Integração da Faixa de Fronteira e da experiência dos municípios integrantes do Consórcio Intermunicipal da Fronteira (CIF), criado em 2009. O método utilizado é o analítico e de pesquisa bibliográfica. A pesquisa evidenciou os seguintes resultados: a)- a autonomia dos municípios não está isolada da Federação brasileira; b)- a Constituição da República Federativa de 1988 estabeleceu as matérias próprias de cada um dos entes da Federação; c)- a instalação dos Núcleos Regionais dos Estados do Paraná e Santa Catarina e a experiência da atuação dos municípios integrantes do Consórcio Intermunicipal da Fronteira (CIF) aperfeiçoam a gestão das políticas públicas e o desenvolvimento da integração regional da fronteira entre Brasil e Argentina. A conclusão aponta que a autonomia dos municípios brasileiros concorre para o equilíbrio interno da Federação e se fortalece cada vez mais no contexto da atual conjuntura política e econômica que liga o global ao local e vice-versa. Ainda, os Núcleos Estaduais de Santa Catarina e Paraná de Integração da Faixa de Fronteira e a experiência dos municípios do Consórcio Intermunicipal da Fronteira (CIF) indicam importantes caminhos de fortalecimento do desenvolvimento da integração regional de fronteira.
\end{abstract}

Palavras-chave: Autonomia. Desenvolvimento. Integração regional. Municípios.

Abstract: The main objective of this article is to analyze the autonomy of the Brazilian municipalities in the federative system, passing on their analysis on the development of the regional integration of the border region between Brazil and Argentina, starting from the installation in 2011 of the Integration Nuclei of the Border Range States of Santa Catarina and Paraná and the experience of the municipalities belonging to the Consórcio Intermunicipal da Fronteira (CIF), created in 2009. The method used is analytical and bibliographic research. The research evidenced the following results: a) - the autonomy of the municipalities is not isolated from the Brazilian Federation; b) - the Constitution of the Federative Republic of 1988 established the specific subjects of each of the entities of the Federation; c) - The installation of the Regional Centers of the States of Parana and Santa Catarina and the experience of the activities of the municipalities that started the Consórcio Intermunicipal da Fronteira (CIF) improve the management of public policies and the development of the regional integration of the border between Brazil and Argentina. Conclusion: the autonomy of the Brazilian municipalities competes for the internal balance of the Federation and is strengthened increasingly in the context of the current political and economic conjuncture that links the global to the local and vice versa. In addition, the State Stations of Santa Catarina and Paraná for Integration of the Border Strip and the experience of the Municipalities of the Consórcio Intermunicipal da Fronteira (CIF) point out important ways of strengthening the development of regional border integration.

Keywords: Autonomy. Development. Regional integration. Municipalites.

\footnotetext{
${ }^{1}$ Doutor em Direito. Professor do Programa de Pós-Graduação em Políticas Sociais e Dinâmicas Regionais da UNOCHAPECÓ. canzi@unochapeco.edu.br

2 Doutora em Ciências Humanas. Professora do Programa de Pós-Graduação em Políticas Sociais e Dinâmicas Regionais da UNOCHAPECÓ. aldana@unochapeco.edu.br
} 


\section{Introdução}

A integração regional constitui-se em importante forma de fortalecimento institucional dos municípios fronteiriços, a partir de processos participativos, com o objetivo de diminuir as desigualdades e buscar o efetivo desenvolvimento. A atuação dos munícipios torna-se decisiva porque é a partir do local e seu entorno que se processa acentuadamente a integração regional na faixa de fronteira.

A problematização do tema objeto se desenvolve tomando por referência a abordagem sobre a autonomia relativa dos municípios e o desenvolvimento da integração regional de fronteira. A criação dos Núcleos Estaduais de Santa Catarina e Paraná de Integração da Faixa de Fronteira, respectivamente, se processou em 24 de novembro de 2011 e em 27 de agosto de 2012, inserindo-se no debate sobre o aperfeiçoamento da gestão das políticas públicas, para o desenvolvimento da faixa de fronteira, estimulando a articulação com os governantes locais. Ao mesmo tempo, a experiência dos municípios integrantes do Consórcio Intermunicipal da Fronteira (CIF), integrado por Dionísio Cerqueira Dionísio (SC), Bom Jesus do Sul e Barracão (PR) e de Bernardo de Irigoyen (Argentina), evidencia a produção de um desenvolvimento digno de registro na abordagem da integração regional na faixa de fronteira entre o Brasil e a Argentina.

A formulação de diferentes políticas para a cooperação, integração e desenvolvimento das localidades situadas em faixa de fronteira vem sendo estimulada pelos governos do Brasil e Argentina, a exemplo da Lei Federal no 26.523/2009 da República Federal Argentina e do Decreto Federal da República Federativa do Brasil no 8.636, de 13 de janeiro de 2016', cuja proposta é facilitar a convivência das localidades fronteiriças vinculadas e impulsar sua integração por meio de um tratamento diferenciado à população em matéria econômica, de trânsito, de regime trabalhista e de acesso aos serviços públicos e de educação.

A ordenação do texto prima pela abordagem preliminar sobre a Federação Brasileira, seguida da inserção temática dos Núcleos Estaduais de Santa Catarina e Paraná de integração da faixa de fronteira, da autonomia constitucional municipal e da experiência de integração e desenvolvimento dos municípios do Consórcio da Fronteira (CIF). 


\section{A Federação Brasileira}

A história da Federação no Brasil está diretamente vinculada à formação sócio-política, econômica, jurídica e cultural da Sociedade Brasileira. Referida formação insere a emancipação política, a progressiva formação econômica, a edificação das instituições sociais, da normatividade constitucional e da cultura do povo brasileiro.

A Federação brasileira teve seu referencial inicial estruturante a partir da Constituição de $1891^{2}$, com forte influência, à época, do modelo adotado pela Constituição dos Estados Unidos da América.

No caso do Brasil, houve a adoção constitucional da forma Republicana de governo e da federação como forma de Estado ${ }^{3}$. Na Federação os entes integrantes são dotados de capacidade política e na condição de Pessoas Jurídicas podem legislar criando normas abstratas com força vinculante no ordenamento jurídico. Isto significa que o Estado para melhor atingir seus objetivos adota subdivisões internas, com distribuição de competências e atribuições, entre a União, Estados membros, Distrito Federal e Municípios.

Na definição do constitucionalista José Afonso da Silva (1992), competência é a 'faculdade juridicamente atribuída a uma entidade, órgão ou agente do poder público para emitir decisões. Competências são as diversas modalidades de poder que servem aos órgãos ou entidades estatais para realizar suas funções.

A repartição de competências entre os entes da Federação pode ocorrer na dimensão constitucional ou administrativa. Uma vez estabelecidas as competências, os entes integrantes da Federação passam a legislar e atuar em todas as matérias envolvendo a sua esfera de delegação.

O artigo 21 da Constituição Brasileira de 1988 estabelece que é competência da União manter relações com outros Estados estrangeiros, por meio da celebração de tratados internacionais. Nas relações internacionais, a União não atua como ente federado parcial, como componente da federação brasileira, mas congrega todos os demais entes federados para representar a República Federativa do Brasil. Portanto, a União ora atua como ordem jurídica global, representando o Estado brasileiro, ora como ente federado, como pessoa jurídica de direito público interno.

No contexto atual, a federação brasileira encontra-se em pleno fortalecimento 
político- administrativo, com destaque para a cooperação ${ }^{4}$ entre a União, Estados membros, Distrito Federal e seus cinco mil quinhentos e setenta municípios. Tal assertiva se justifica em virtude da cooperação que pode ser estabelecida entre as diferentes esferas da federação para a promoção do desenvolvimento territorial e do bem-estar da população. Ainda, a federação brasileira reflete seu vigor na realidade internacional dada as relações políticas e econômicas na ordem externa com outros países.

O Brasil integra o grupo de países que na contemporaneidade adotaram o modelo federativo, ao lado de Estados, a exemplo dos Estados Unidos da América, Canadá, Alemanha, Argentina e Venezuela, entre outros. Para o internacionalista Seitenfus, a integração regional é complexa devido a ligação existente entre realidade interna e política externa:

[...] a atuação externa dos Estados e dos outros atores internacionais não pode ser compreendida sem a devida análise das condições internas que a motivam. Ou seja, existe um estreito vínculo entre a percepção ideológica de um governo e sua atuação internacional. Mesmo podendo ser consideradas como a mais constante das políticas públicas, as atividades externas governamentais sofrem inflexão de prioridades quando há mudança de governo ou de regime político [...]. Portanto, há estreitos liames entre realidade interna e política externa. (SEITENFUS, 2003, p.43)

No caso do Brasil, a Constituição de 1988 estabeleceu o rol taxativo de princípios ${ }^{5}$ que a República Federativa do Brasil deve primar nas relações internacionais, além de buscar a integração nas esferas econômica, política, social e cultural, objetivando a formação de uma Comunidade Latino Americana de Nações ${ }^{6}$ :

Art. 4ㅇA República Federativa do Brasil rege-se nas suas relações internacionais pelos seguintes princípios: I - independência nacional; II - prevalência dos direitos humanos; III - autodeterminação dos povos; IV - não-intervenção; V - igualdade entre os Estados; VI - defesa da paz; VII - solução pacífica dos conflitos; VIII repúdio ao terrorismo e ao racismo; IX - cooperação entre os povos para o progresso da humanidade; $X$ - concessão de asilo político. Parágrafo único. A República Federativa do Brasil buscará a integração econômica, política, social e cultural dos povos da América Latina, visando à formação de uma comunidade latino-americana de nações.

Portanto, a complexidade anunciada desafia a Federação brasileira a promover ações para o efetivo desenvolvimento da integração regional nas esferas econômica, política, social e cultural. 


\section{Os Núcleos Estaduais de Santa Catarina e Paraná de Integração da Faixa de Fronteira}

Para a compreensão das relações de fronteira é necessário inserir a abordagem sobre os Núcleos Estaduais de Santa Catarina e Paraná de Integração da Faixa de Fronteira, delineadores importantes do recorte temático objeto da pesquisa. A Comissão Permanente para o Desenvolvimento e a Integração da Faixa de Fronteira (CDIF), instituída por Decreto de 08 de setembro de 2010, vinculada ao Ministério da Integração Nacional, formada por 20 (vinte) órgãos do governo federal e 8 (oito) entidades convidadas, possui atribuição de contribuir para o aperfeiçoamento da gestão das políticas públicas para o desenvolvimento da faixa de fronteira, estimulando a articulação com os governantes locais.

A atuação da CDIF busca promover o desenvolvimento socioeconômico dos municípios brasileiros localizados na faixa de fronteira ${ }^{7}$, contemplando as seguintes unidades federativas: Amapá, Pará, Roraima, Amazonas, Acre, Rondônia, Mato Grosso, Mato Grosso do Sul, Paraná, Santa Catarina e Rio Grande do Sul. Em específico, no que tange aos Estados do Paraná e Santa Catarina, o Ministério da Integração Nacional, respectivamente, em 24 de novembro de $2011^{8}$ e em 27 de agosto de $2012^{9}$, participou da instalação oficial dos Núcleos Regionais para o Desenvolvimento e Integração da Faixa de Fronteira.

O Decreto 3.324, de 25 de novembro de 2011, publicado no Diário Oficial no 8.596, de 25 de novembro de 2011, institui o Núcleo Regional para o Desenvolvimento e Integração da Faixa de Fronteira do Estado do Paraná e conferiu providências correlatas (GOVERNO DO ESTADO DO PARANA, 2011). O Decreto $\mathrm{n}^{\circ}$ 1.121, de 14 de agosto de 2012 criou o Núcleo Estadual de Integração da Faixa de Fronteira do Estado de Santa Catarina (NFSC) com a finalidade de propor e coordenar ações que tenham por objetivo o desenvolvimento de iniciativas aptas a possibilitar a adequada atuação do Estado nas suas regiões de fronteira (GOVERNO DE ESTADO DE SANTA CATARINA, 2013).

Entre as ações do NFPR - com sede no Parque Tecnológico Itaipu (PTI) encontram-se os projetos para o desenvolvimento da região de fronteira, como o Beira Foz, Plataforma Logística Binacional Guaíra-Salto Del Guairá e a Ferrovia eixo Maracaju, no Mato Grosso do Sul, a Guaíra, Cascavel, Guarapuava e Ponta do Poço. Outras ações são desenvolvidas de forma conjunta e integrada com os projetos de setores estratégicos, como turismo, saúde, água e biotecnologia (GOVERNO DE ESTADO DE SANTA CATARINA, Secretaria de 
Estado e Planejamento, 2016).

O Núcleo Estadual de Integração da Faixa de Fronteira do Estado de Santa Catarina (NFSC) é coordenado pela Secretaria de Estado do Planejamento e conta com o assessoramento técnico de oito Câmaras Temáticas (nas áreas da Educação, Saúde, Infraestrutura e Logística, Controle e Segurança, Desenvolvimento Econômico, Desenvolvimento Socioambiental, Agricultura, Pecuária e Pesca e Turismo, Cultura e Esporte), cujos focos de atuação correspondem às prioridades definidas no Plano de Desenvolvimento e Integração Fronteiriço de Santa Catarina (PDIF/SC) ${ }^{10}$. A Faixa de Fronteira Catarinense abrange 82 municípios dentro do espaço territorial de $150 \mathrm{~km}$ que adentra ao interior do Estado, a partir da linha limítrofe entre o Estado de Santa Catarina e o país vizinho, a Argentina.

Os Núcleos Estaduais de Santa Catarina e Paraná de Integração da Faixa de Fronteira caracterizam importantes mecanismos de fortalecimento da gestão das políticas públicas e para o desenvolvimento regional, estimulando a articulação com os governantes locais, embora se reconheça os limites da atuação prática dos referidos Núcleos, considerada a política econômica brasileira vigente e seus reflexos regionais na atualidade.

\section{A autonomia constitucional municipal}

No que se refere às competências dos municípios, a Constituição da República Federativa do Brasil, assim estabelece:

Art. 30. Compete aos Municípios: I - legislar sobre assuntos de interesse local; II suplementar a legislação federal e a estadual no que couber; III - instituir e arrecadar os tributos de sua competência, bem como aplicar suas rendas, sem prejuízo da obrigatoriedade de prestar contas e publicar balancetes nos prazos fixados em lei; IV

- criar, organizar e suprimir distritos, observada a legislação estadual; V organizar e prestar, diretamente ou sob regime de concessão ou permissão, os serviços públicos de interesse local, incluído o de transporte coletivo, que tem caráter essencial; VI - manter, com a cooperação técnica e financeira da União e do Estado, programas de educação infantil e de ensino fundamental; VII - prestar, com a cooperação técnica e financeira da União e do Estado, serviços de atendimento à saúde da população; VIII

- promover, no que couber, adequado ordenamento territorial, mediante planejamento e controle do uso, do parcelamento e da ocupação do solo urbano; IX - promover a proteção do patrimônio histórico-cultural local, observada a legislação e a ação fiscalizadora federal e estadual. ( BRASIL, CF, 1988). 
Com a Constituição de 1988 o município teve ampliada a sua autonomia quanto ao campo de competências de atuação, com destaque para legislar, com fundamento na independência constitucional que lhe é inerente sobre os assuntos referidos no artigo 30, I, II, III, IV da CF.

Também, em matéria organizacional, o município tem competência administrativa sobre os assuntos dos incisos IV, V, VI da CF. Além disso, o município possui competência quanto à promoção humana e da promoção do patrimônio histórico, conforme dispõe o artigo 30, VII, VIII, IX da CF.

O status constitucional de ente federativo atribuído ao (s) município(s) assegura-lhe(s) autonomia $^{11}$ nos aspectos: político, administrativo, financeiro, legislativo e autoorganizatório (artigos 29 a 31, 156, 158 e 159 da CF). Também, a Constituição possibilitou ao município editar sua lei orgânica própria; extinguiu a nomeação de prefeitos pelos governadores e manteve a eleição direta de vereadores (art. 29, CF); atribuiu competência privativa para legislar sobre interesse local (art. 30, I, CF); ampliou a competência impositiva para criar tributos (art. 156, CF); e aumentou a participação municipal nos impostos partilhados (artigos 158 e 159, § 3으, da CF).

Ataliba Nogueira defende que não há município com vida, se as autoridades nele apenas residem e se as próprias autoridades locais esperam a palavra ou a ajuda, que venha de fora. Não há ninguém mais interessado nos assuntos locais do que os munícipes. Sem independência não há efetiva autonomia política, econômica e financeira dos Municípios. Este mesmo autor deixa transparecer, em sua teoria, que a existência autônoma do município é condição real e efetiva para que referido ente seja sujeito efetivo de direito, cabendo apenas o reconhecimento formal pela lei do Estado. (NOGUEIRA et al., 2011. p. 840-841).

Registra-se aqui que no Brasil a importância da autonomia dos municípios fortalece a criação de mecanismos com efetivo desenvolvimento de seu papel na produção do espaço glocal. O glocal aproxima a perspectiva conceitual de global-local à de universal e particular. (ROBERTSON, 1999). A glocalização do espaço se produz a partir do complexo que envolve o local e seu entorno, sem desmerecer as zonas de influência do global. (DOWBOR, 1998, p.33) $)^{12}$. O local e seu entorno assumem importância e força em "carne e osso", pois insere a produção do espaço vivido pelo cidadão e seus atores no território. O local serve de 
referência para o global, transpondo a análise de ser apenas determinado pelo global. (ARNOUD, 2000, p. 360) ${ }^{13}$. A autonomia dos municípios e sua localização estratégica concorrem para o desenvolvimento da integração regional de fronteira, consoante experiência problematizada a seguir.

\section{A experiência de integração e desenvolvimento dos municípios do Consórcio Intermunicipal da Fronteira (CIF)}

A experiência dos municípios do Consórcio Intermunicipal da Fronteira (CIF) confere a base de análise específica sobre o desenvolvimento da integração regional da Faixa de Fronteira entre Brasil e Argentina. Com a nomenclatura de "Bases para uma Proposta de Desenvolvimento e Integração da Faixa de Fronteira", o documento do Ministério da Integração Nacional Brasileiro aponta para a necessidade de criação de mecanismos eficientes de empoderamento institucional dos municípios fronteiriços, a partir de processos participativos e democráticos, dos quais deverão emergir propostas de ações para o desenvolvimento e efetiva integração da respectiva faixa de fronteira (BRASIL, 2010).

Entre os anunciados mecanismos encontram-se os Consórcios Intermunicipais Públicos. A previsão jurídico-institucional para formação de Consórcios Intermunicipais administrativos remonta à Constituição de 1937, que em seu artigo 2914 conferia guarida para que municípios da mesma Região pudessem integrar agrupamentos dotados de personalidade jurídica limitada a seus fins, objetivando a instalação, exploração e administração de serviços comuns. Entretanto, a implementação mais efetiva dos referidos Consórcios Públicos se processou a partir da década de 1980 (IBGE, 2012).

A Lei 11.107, de 06 de abril de 2005, instituiu as normas gerais para contratação de consórcios públicos e regulamentou o artigo 241 da Constituição Federal15 de 1988, já atingida pela reforma da Emenda de no 19 (Reforma do Estado no Brasil). O Decreto 6.017, de 17 de janeiro de 2007 regulamentou a Lei no 11.107, de 6 de abril de 2005, que dispõe sobre normas gerais de contratação de consórcios públicos (BRASIL. Decreto n.6.017, 2007).

A experiência da ordenação político-jurídica e administrativa dos municípios de Dionísio Cerqueira (SC), Barracão e Bom Jesus do Sul (PR) situados em território brasileiro e de Bernardo de Irigoyen, Província de Misiones - República Federativa da Argentina, caracteriza um marco diferencial e concreto de uma práxis de produção do espaço glocal, via 
criação de mecanismos eficientes de empoderamento institucional entre os referidos municípios fronteiriços, a partir de processos participativos e democráticos, dos quais se destaca o Consórcio Intermunicipal da Fronteira (CIF). O CIF foi criado em 2009 com o objetivo de promover a integração como meio de dinamizar o processo de desenvolvimento econômico e social a partir do lugar onde referidos municípios estão estrategicamente inseridos.

O CIF contou com importante parceria do Serviço de Apoio às Micro e Pequenas Empresas (SEBRAE) que desenvolveu o Programa LIDER para o Desenvolvimento Regional, reunindo os setores público, privado e terceiro setor, de 39 municípios da região de fronteira Brasil/Argentina: Sudoeste do Paraná, Extremo Oeste de Santa Catarina e Extremo Leste de Misiones. A proposta de desenvolvimento desse território foi definida com ações integradas com a visão de ser referência no MERCOSUL em qualidade de vida com excelência na educação, turismo, agroecologia e produtos locais (CIF - Consórcio Intermunicipal da Fronteira, 2016).

Entre os fatores que favoreceram a constituição do CIF foram destaque: vivência de problemas comuns, existência de legislação brasileira sobre consórcios públicos intermunicipais (Lei no 11.107, de 06 de abril de 2005 e Decreto 6.017, de janeiro de 2007), identificação territorial, amadurecimento e vontade política, carência de recursos, localização geográfica da fronteira. Quanto às vantagens, foram elencadas: fortalecimento e visibilidade dos municípios e da região perante os demais órgãos e escalas governamentais, inclusive no âmbito internacional - Argentina; integração e ampliação do olhar para a noção de região, criação de identidade regional; avanço dos serviços públicos, com maior efetividade das ações; enfrentar e solucionar problemas em comum, otimizar o tempo e recursos; parceria internacional com o apoio do município argentino; conjunção de esforços para buscar o desenvolvimento coletivo, com olhos no entorno regional; amadurecimento político; maior facilidade de acesso a recursos públicos nas demais esferas governamentais; fortalecimento e apoio das demais escalas governamentais; amadurecimento do senso de cooperação e integração local e regional; elaboração de projetos mais consistentes e viáveis. (HENRICHS, 2015, p.101-103).

A criação do CIF teve amparo na Constituição Federal (artigo 241), na Lei 11.107, de 06 de abril de 2005, no Decreto 6.017, de 17 de janeiro de 2007, no protocolo de intenções e na 
regulamentação que vier a ser adotada por seus órgãos competentes, conforme determina o art. 1ำ do Estatuto Social. Portanto, o CIF foi constituído sob a forma de associação pública, com personalidade jurídica de direito público e natureza autárquica.

Entretanto, por ausência de regulamentação transnacional, o município de Bernardo de Irigoyen (Misiones) da Argentina, participa do CIF como integrante de fato, consoante comprovam as atas de reuniões, protocolo de intenções assinado entre os entes subnacionais, o regulamento do Gabinete de Gestão Integrada (GGI), entre outros.

Não se pode negar que apesar da ausência de uma regulamentação mais específica por parte da República Federativa Argentina em relação aos Consórcios intermunicipais públicos, resta evidenciado que há um esforço em construir uma agenda comum, com o objetivo de debater as problemáticas das fronteiras entre Brasil e Argentina. Neste sentido, o município de Bernardo de Irigoyen sediou em 13 de janeiro de 2016 o 20 Encontro Binacional de Cidades Fronteiriças vinculadas, com a participação de órgãos federais e subnacionais do Brasil e da Argentina. A base do debate se processou a partir do disposto na Lei Federal no 26.523/2009 da República Federal Argentina e no Decreto Federal da República Federativa do Brasil no 8.636, de 13 de janeiro de 201616, cuja proposta é facilitar a convivência das localidades fronteiriças vinculadas e impulsar sua integração por meio de um tratamento diferenciado à população em matéria econômica, de trânsito, de regime trabalhista e de acesso aos serviços públicos e de educação. (CIF, 2016).

É expressiva a atuação do Consórcio Intermunicipal da Fronteira, desde 2009, em ações de planejamento, instrumentalização e execução, com a finalidade de incrementar o desenvolvimento econômico e social da fronteira em que se situam os municípios de Dionísio Cerqueira, Barracão, Bom Jesus do Sul e de Bernardo de Irigoyen.

Em data de 03 de março de 2011 houve a formalização de protocolo de intenções (CIF, 2016, CADERNO DAS AÇÕES INTEGRADAS, p. 35) entre os municípios de Dionísio Cerqueira (SC), Barracão e Bom Jesus do Sul (PR) situados em território brasileiro, e de Bernardo de Irigoyen, Província de Misiones - República Federativa da Argentina, com os Governos de Santa Catarina, Paraná e Misiones (Argentina), para o desenvolvimento de atividades integradas, contemplando o planejamento e execução das seguintes ações:1) Parque Turístico Ambiental de Integração - Brasil/Argentina;2) Estrutura Líder - Caminhos da Fronteira;3) Construção Aduana Integrada de Turistas;4) Projeto Urbanístico Integrado com 
a Identificação das divisas Paraná, Santa Catarina, Misiones;5) Recursos para Custeio de Atendimentos Hospitalares;6) Saneamento Básico: Implantação da Rede Coletora de Esgoto Sanitária e rede de distribuição de água integrada Brasil/Argentina;7) Terminal Rodoviário Integrado Paraná, Santa Catarina, Misiones;8) Melhoria da Malha viária através de adequação de estradas e pavimentação com pedras irregulares;9) Apoio Institucional dos Governadores para a Implantação da Universidade Pública e Gratuita;10) Para Aprovação Projeto de Lei Congresso Nacional do Brasil - que trata do acordo Brasil/Argentina Localidade Fronteiriça Vinculada; Já transformando em Lei e reconhecido - Lei 26.523, de 10.10.2009, pelo Congresso Argentino;11) Estruturação e Melhorias Aduana Integrada de cargas - Porto Seco Dionísio Cerqueira;12) Apoio e estrutura para o fornecimento da produção na agricultura. O referido protocolo foi formalmente assinado pelos Governadores dos Estados do Paraná e Santa Catarina, Governador do Estado de Misiones-Argentina, Ministro de Turismo de Misiones- Argentina, Secretário do Estado de Santa Catarina-SDR Dionísio Cerqueira, Prefeitos de Dionísio Cerqueira (SC), Barracão (PR), Bom Jesus do Sul (PR), Intendente de Bernardo de Irigoyen-Argentina.

O Consórcio Intermunicipal da Fronteira, com a finalidade de incrementar o desenvolvimento econômico e social no âmbito de sua abrangência, planejou, instrumentalizou e executou significativas ações glocalizadas no âmbito de sua atuação, a saber: a) ações no âmbito do Planejamento e desenvolvimento Regional; b) ações de infraestrutura para o desenvolvimento econômico; c) ações na área do Turismo; d) ações na área da saúde; e) ações na área da educação; f) ações na área do urbanismo e meio ambiente; g) ações na área da habitação; h) ações na área de Previdência Social; i) ações na área Rodoviária; j) ações na área da agricultura; I) ações na área de segurança pública.

A experiência retratada evidencia a articulação do Consórcio intermunicipal da Fronteira na produção do espaço glocal, capaz de responder com maior eficiência às demandas que vincula a área fronteiriça de abrangência, com melhores condições de negociação dos municípios do CIF com os governos subnacionais e federal, bem como na escala transnacional. 


\section{Considerações finais}

Não se pode versar sobre a autonomia dos municípios brasileiros de forma isolada à Federação da qual fazem parte. As relações entre os entes da Federação interferem significativamente no modo de atuação prática dos municípios, considerada a repartição de competências e atribuições conferidas constitucionalmente. Logo, a autonomia dos municípios é relativa, uma vez há matérias que necessitam da anuência do Estado ou da União, a exemplo das relações externas com outros Estados, Províncias ou Países.

Foi constatado que os Núcleos Estaduais de Santa Catarina e Paraná de Integração da Faixa de Fronteira apresentam limites em seu âmbito de atuação, incluindo a própria fundação destes que ocorreu em decorrência das demandas impostas pela realidade da fronteira e após a criação do Consórcio Intermunicipal da Fronteira (CIF), conforme consignado no texto. Por outro lado, é de reconhecimento público de que os referidos Núcleos de Integração da Faixa de Fronteira contribuem no aperfeiçoamento da gestão das políticas públicas e articulação comos governantes locais para o desenvolvimento da faixa de fronteira.

Também, registra-se que a autonomia de fato (especificidade da vida cotidiana do local e seu entorno) e de direito, relativas ao exercício das competências dos municípios brasileiros, concorrem para o equilíbrio interno da Federação e se fortalecem cada vez mais no contexto da atual conjuntura política e econômica que liga o global ao local e vice-versa, provocadoras de uma significativa flexibilização da soberania Estatal centralizada, em tempos de grandes mudanças de paradigmas que atingem as diferentes perspectivas de desenvolvimento e integração regional.

Por derradeiro, a experiência dos municípios do Consórcio Intermunicipal da Fronteira (CIF) revela a produção do espaço social, político, econômico e cultural, a partir da prática do local e seu entorno, caracterizada por um desenvolvimento de integração regional na fronteira, muitas vezes à margem da efetiva presença e apoio dos governos subnacionais dos Estados e centrais do Brasil e Argentina. 
Notas

1 Promulga o Acordo entre a República Federativa do Brasil e a República Argentina sobre Localidades Fronteiriças Vinculadas, firmado em Puerto Iguazú, em 30 de novembro de 2005.

2 Art. 10 da Constituição de 1891: "A Nação brasileira adota como forma de Governo, sob o regime representativo, a República Federativa, proclamada a 15 de novembro de 1889, e constitui-se, por união perpétua e indissolúvel das suas antigas Províncias, em Estados Unidos do Brasil.

${ }^{3}$ Art. 1ㅇ da Constituição de 1988: “A República Federativa do Brasil, formada pela união indissolúvel dos Estados e Municípios e do Distrito Federal, constitui-se em Estado Democrático de Direito e tem como fundamentos: I - a soberania; II - a cidadania; III - a dignidade da pessoa humana; IV - os valores sociais do trabalho e da livre iniciativa; $\mathrm{V}$ - o pluralismo político".

${ }^{4}$ No que diz respeito a forma de cooperação entre os entes integrantes da República Federativa do Brasil, a Constituição Federal de 1988, assim dispõe: Art. 23. É competência comum da União, dos Estados, do Distrito Federal e dos Municípios. Parágrafo único. Leis complementares fixarão normas para a cooperação entre a União e os Estados, o Distrito Federal e os Municípios, tendo em vista o equilíbrio do desenvolvimento e do bem-estar em âmbito nacional; Art. 241. A União, os Estados, o Distrito Federal e os Municípios disciplinarão por meio de lei os consórcios públicos e os convênios de cooperação entre os entes federados, autorizando a gestão associada de serviços públicos, bem como a transferência total ou parcial de encargos, serviços, pessoal e bens essenciais à continuidade dos serviços transferidos.

${ }^{5}$ Os princípios cumprem caráter de fundamentalidade no sistema das fontes do direito, constituindo-se em normas de natureza ou com um papel fundamental no ordenamento jurídico devido à sua posição hierárquica no sistema das fontes. (CANOTILHO, 1998, p. 1086-87).

${ }^{6}$ O Mercosul foi criado em 1991, pelo Tratado de Assunção. Somente em 1995, com a entrada em vigor do Protocolo de Ouro Preto, os Estados decidiram criar a personalidade jurídica do Mercosul. Trata-se agora de uma Organização Internacional. O Mercosul tinha como membros originais Argentina, Brasil, Paraguai e Uruguai. Em 2005 houve a adesão da Venezuela, cuja efetivação necessita da concordância dos Parlamentos Nacionais. (VARELA, 2011. p. 375).

${ }^{7}$ A Fronteira é resultante de um processo histórico que tem por base a preocupação do Estado com a garantia de sua soberania e independência nacional desde os tempos da Colônia. Historicamente, o país tem demonstrado interesse pela região que envolve a fronteira, ao buscar identificá-la como faixa de fronteira e, como tal, dotada de complexidade e peculiaridades que a tornam especial em relação ao restante do país. (BRASIL, MINISTÉRIO DA INTEGRAÇÃO NACIONAL, 2010).

8 Foi instalado oficialmente em 24 de novembro de 2001 o Núcleo Regional para o Desenvolvimento e Integração da Faixa de Fronteira do Estado Paraná, que vai integrar as três esferas governamentais no planejamento e execução de ações voltadas para o desenvolvimento da região. O Decreto que cria o núcleo foi assinado em Foz do Iguaçu pelo governador Beto Richa, pelo ministro da Integração Nacional, Fernando Coelho Bezerra, e pelo secretário de Estado de Turismo, Faisal Saleh. Fruto de parceria entre o governo federal, o Estado e os municípios da região, o núcleo vai reunir representantes de mais de 20 órgãos e entidades, sob a coordenação da Secretaria do Turismo. A faixa paranaense fronteiriça é, entre todas as existentes no Brasil, a que possui o maior contingente populacional. Formada por 139 municípios, localizados em grande parte nas regiões Oeste e Sudoeste, ela tem 150 quilômetros de largura e 16 mil quilômetros de extensão. A área de fronteira do País engloba $27 \%$ do território nacional e abriga uma população de mais de 10 milhões de habitantes, distribuídos em 588 municípios de 11 estados, que fazem fronteira com 10 países. (AGÊNCIA DE NOTÍCIAS DO PARANÁ, 24 jun. 2011).

${ }^{9}$ Na manhã da terça-feira, 27 de agosto de 2013, foi realizado na Câmara de Vereadores de Dionísio Cerqueira, o ato de instalação do Núcleo Estadual de Integração da Faixa de Fronteira do Estado de Santa Catarina (NFSC). A reunião de trabalho foi prestigiada por mais de cem pessoas representando a região da faixa de fronteira catarinense que abrange 85 municípios, agrupados em 11 Secretarias de Desenvolvimento Regional (SDRs), compreendendo um contingente de 13,3\% da população catarinense. (GOVERNO DE SANTA CATARINA, NFSC, 27 ago. 2013). 
10 O Plano de Desenvolvimento e Integração Fronteiriço de Santa Catarina foi elaborado por cerca de 300 representantes de 60 instituições dos setores público e privado, instituições de ensino superior e pesquisa e entidades representativas da sociedade civil organizada sob a coordenação da Secretaria de Estado do Planejamento, com apoio do Sebrae, em 2012 (GOVERNO DE ESTADO DE SANTA CATARINA. SECRETARIA DO ESTADO DO PLANEJAMENTO- PDIF, 2012).

${ }^{11}$ Autonomia: Refere-se à capacidade, competências e condições para suportar responsabilidades, desempenhar tarefas e alcançar objetivos à sua razão de ser. Significa também a independência legislativa e políticoadministrativa/executiva para decidir sobre as questões de sua esfera de competência.

12 "Vivemos uma condição planetária pontuada por intervenções locais, regionais, cujas intensas variações determinam a alternância, mais ainda, a imbricação do local e do global" (DOWBOR, 1998, p.33).

${ }^{13}$ No dizer de Arnoud (2000, p. 360), "uma dialética entre o global e o local, nos vários sentidos, está, portanto, irremediavelmente instituída. É um aspecto que nenhuma pesquisa sociológica pode ignorar, porque se trata de examinar o direito e os sistemas jurídicos em geral"

14 "Os municípios da mesma região podem agrupar-se para a instalação, exploração e administração de serviços públicos comuns. O agrupamento, assim constituído, será dotado de personalidade jurídica limitada a seus fins. Parágrafo único - Caberá aos Estados regular as condições em que tais agrupamentos poderão constituir-se, bem como a forma, de sua administração" (BRASIL. CF 1937, art. 29).

15“A União, os Estados, o Distrito Federal e os Municípios disciplinarão por meio de lei os consórcios públicos e os convênios de cooperação entre os entes federados, autorizando a gestão associada de serviços públicos, bem como a transferência total ou parcial de encargos, serviços, pessoal e bens essenciais à continuidade dos serviços transferidos" (BRASIL. CF 1988, art. 241).

16 Promulga o Acordo entre a República Federativa do Brasil e a República Argentina sobre Localidades Fronteiriças Vinculadas, firmado em Puerto Iguazú, em 30 de novembro de 2005. (BRASIL. Decreto n. 8.636, 2016).

\section{Referências}

AGÊNCIA DE NOTíCIAS DO PARANÁ. Paraná instala Núcleo de Desenvolvimento e Integração da Faixa de Fronteira. 24 jun. 2011. Disponível em: <http://www.aen.pr.gov.br/modules/noticias/ article.php?storyid=66643>. Acesso em: 06 jun. 2016.

ARNAUD, André-Jean; DULCE, María José Fariñas. Introdução à análise dos sistemas jurídicos. Trad. Eduardo Pellew Wilson. Rio de Janeiro: Renovar, 2000.

BRASIL. Constituição dos Estados Unidos do Brasil (de 10 de novembro de 1937). Disponível em: <http://www.planalto.gov.br/ccivil_03/Constituiçao/Constituicao37.htm>. Acesso em: 05 jun. 2016.

CANZI, I. A Práxis da Produção do Espaço Jurídico-político Glocal pelos municípios do Consórcio Intermunicipal da Fronteira(CIF). SEQUENCIA, v. 39, p. 219-248, 2018.

. Constituição da República Federativa dos Estados Unidos do Brasil de 1891. Rio de Janeiro, 1891. Disponível em:

<http://www.planalto.gov.br/ccivil_03/Constituicao/Constituicao91.htm>. Acesso em: 2 ago. 2016. 
. Constituição da República Federativa do Brasil de 1988. Brasília, 1988. Disponível em: <http://www.planalto.gov.br/ccivil_03/Constituicao/Constituicao.htm>. Acesso em: 05 jun. 2016.

Decreto n. 6.017, de 17 de janeiro de 2007. Regulamenta a Lei n. 11.107, de 6 de abril de 2005, que dispõe sobre normas gerais de contratação de consórcios públicos. Disponível em:<http://www.planalto.gov.br/ccivil_03/_ato20072010/2007/decreto/d6017.htm>. Acesso em: 05 jun. 2016.

Ministério da Integração Nacional. Grupo de trabalho integração Fronteiriça. Bases para uma proposta de desenvolvimento e integração da faixa de fronteira. Brasília: Kaco Gráfica, 2010. 142 p. Disponível em:

<http://www.mi.gov.br/c/document_library/get_file?uuid=ab3fdf20-dcf6-43e1-9e64d6248ebd1353\&groupld=10157>. Acesso em: 6 jun. 2016.

. Decreto n. 8.636, de 13 de janeiro de 2016. Promulga o Acordo entre a República Federativa do Brasil e a República Argentina sobre Localidades Fronteiriças Vinculadas, firmado em Puerto Iguazú, em 30 de novembro de 2005. Disponível em: <http://www.planalto.gov.br/ccivil_03/_Ato2015-2018/2016/Decreto/D8636.htm>. Acesso em: 25 ago. 2016.

CANOTILHO, José Joaquim Gomes. Direito constitucional. 4. ed. Coimbra: Livraria Almedina, 1998.

CIF - Consórcio Intermunicipal da Fronteira. Estatuto do Consórcio Intermunicipal da Fronteira (CIF) adequado à Lei Federal n. 11.107/2005 e ao Decreto Federal n. 6.017/2007. Dispõe sobre normas gerais de contratação de consórcios públicos. Barracão, 27 dez. 2010. Disponível em: <http://cifronteira.com.br/wp-content/uploads/2014/05/Estatuto-doCIF.pdf>. Acesso em: 25 ago. 2016.

Caderno das ações integradas. 2. ed. Barracão: CIF, 2013.

Resolução 22/2013. Nomeia os Membros Efetivos do Gabinete de Gestão Integrada Intermunicipal - GGI-I. Barracão, 24 set. 2013. Disponível em: <http://cifronteira.com.br/wp- content/uploads/2014/05/Resolu\%C3\%A7\%C3\%A3o-201322.pdf>. Acesso em: 25 ago. 2016.

. Protocolo de intenções. Alteração conforme leis municipais - Barracão/PR, Lei 1.974/2013, Bom Jesus do Sul/PR, Lei 553/2013, Dionísio Cerqueira/SC, Lei 4.242/2013). Disponível em: <http://cifronteira.com.br/wp-content/uploads/2014/05/PROTOCOLO-DEINTEN\%C3\%87\%C3\%95ES.pdf>. Acesso em: 25 ago. 2016.

Barracão: história. Disponível em:

<http://cifronteira.com.br/institucional/barracao/>. Acesso em: 12 jun. 2016.

. Bernardo de Irigoyen: história. Disponível em:

<http://cifronteira.com.br/institucional/bernardo-de-irigoyen/>. Acesso em: 10 jun. 2016. 
Bom Jesus do Sul: história. Disponível em:

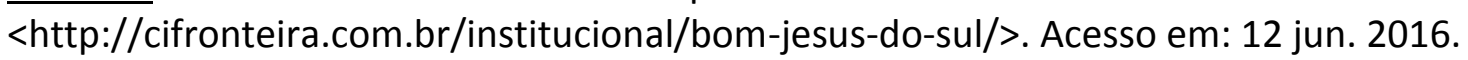

. Caderno das ações integradas. 2. ed. 45 p. Disponível em:

<http://cif.inovecode.com.br/wp-content/uploads/caderno-acoes-cif.pdf $>$. Acesso em: 25 ago. 2016.

Institucional. Disponível em: <http://cifronteira.com.br/institucional/>. Acesso em:

25 ago. 2016.

Resolução 22/2013. Nomeia os Membros Efetivos do Gabinete de Gestão

Integrada Intermunicipal - GGI-I. Barracão, 24 set. 2013. Disponível em:

<http://cifronteira.com.br/wp- content/uploads/2014/05/ Resolu\%C3\%A7\%C3\%A3o-2013-

22.pdf>. Acesso em: 25 ago. 2016.

DOWBOR, Ladislau; IANNI, Octavio; RESENDE, Paulo Edgar A. (org.). Desafios da globalização. Petrópolis, RJ: Vozes, 1998.

ESTADO DO PARANÁ. Prefeitura Municipal de Barracão. Lei n. 1.719/09. Disponível em:<http://cifronteira.com.br/wp-content/uploads/2014/05/LEI-BARRAC+\%C3\%A2O.pdf>. Acesso em: 25 ago. 2016.

GOVERNO DE ESTADO DE SANTA CATARINA. Secretaria de Estado e Planejamento. Decreto $n$. 1.121, de 14 de agosto de 2012. Cria o Núcleo Estadual de Integração da Faixa de Fronteira do Estado de Santa Catarina (NFSC). Disponível em:

<http://server03.pge.sc.gov.br/LegislacaoEstadual/2012/001121-005-0-2012-003.htm>. Acesso em: 06 jun. 2016.

. Secretaria do Estado do Planejamento. Plano de Desenvolvimento e Integração Fronteiriço do Estado de Santa Catarina (PDIF). Florianópolis: Secretaria de Estado e Planejamento, 2012.

. Instalado Núcleo Estadual de Integração da Faixa de Fronteira do Estado de Santa Catarina (NFSC). 27 ago. 2013. Disponível em: <http://sc.gov.br/mais-sobredesenvolvimento-economico/2175-instalado-nucleo-estadual-de-integracao-da-faixa-defronteira-de-santa-catarina>. Acesso em: 06 jun. 2016.

Dionísio Cerqueira. Disponível em: <http://www.sc.gov.br/municipios-d/dionisiocerqueira/> Acesso em: 19 dez. 2015.

GOVERNO DO ESTADO DO PARANÁ. Secretaria de Assuntos Estratégicos. Instalado o Núcleo de Desenvolvimento e Integração da Faixa de Fronteira. 26 nov. 2011. Disponível em:

<http://www.seae.pr.gov.br/modules/noticias/article.php?storyid=98>. Acesso em: 06 jun. 2016.

GOVERNO DO ESTADO DE SANTA CATARINA. Dionísio Cerqueira. Disponível em:<http://www.sc.gov.br/municipios-d/dionisio-cerqueira/> Acesso em: 19 dez. 2015. 
HENRICHS, Joanni Aparecida. Governança multinível para o desenvolvimento regional: um estudo de caso do Consórcio Intermunicipal da Fronteira. 2015. 163 p. Dissertação (Mestrado em Planejamento e Governança Pública) - UTFP-PPGPGP, Curitiba, 2015.

NOGUEIRA, Ataliba et al. Teoria do Município. Revista dos Tribunais - Doutrinas Essenciais. São Paulo, v. III, p. 830-850, 2011.

ROBERTSON, Roland. Globalização: teoria social e cultura global. Petrópolis, RJ: Vozes, 1999.

SEITENFUS, Ricardo Antônio Silva. Manual das organizações internacionais. 2. ed. Porto Alegre: Livraria do Advogado, 2000. 367 p.

. Relações internacionais. Barueri, SP: Manole, 2004.

VARELA, Marcelo. Direito internacional público. 3. ed. São Paulo: Saraiva, 2011. 